LETTERS TO THE EDITOR

\title{
Blunt Or Sharp Needles For Transforaminal Epidurals?
}

\section{To the Editor:}

Derby et al (1) noted that in 2003 approximately half (14/29) of International Spinal Injection Society (ISIS) instructors and the majority (14/17) of poll respondents reported performing transforaminal epidural steroids injections. Do the authors have any data as to needle type (blunt vs sharp) used? If ISIS instructors persist in performing transforaminal injections with sharptipped needles, this would appear to be a resounding rejection of the recent caveats appearing in the interventional pain management literature.

Furthermore, although blunt tipped needles appear to be safe for use around canine renal arteries (2), no information is available to confirm the proposition that they reduce the incidence of serious complications in humans undergoing pain procedures. At this point in time the putative benefit is pure conjecture. Whether or not using blunt needles results in an unanticipated new set of devastating injuries unique to blunt needles remains to be seen; it took quite a few years for the transforaminal complications to surface. Medical history is replete with "improvements" that seemed laudable at the time but later turned out to be as bad as, or worse than, the problems they addressed. The older anesthesia-based interventionalists will recall that once upon a time particulate antacids seemed to be a good idea during parturition. Closer to home, complete bed rest and lumbar traction for low back pain also comes to mind. I believe we crippled quite a few unfortunates with that "common-sense" and intuitively appealing approach when I was an intern.

The authors also correctly point out that those practitioners who have incurred major complications may not have been willing to self-report for this study. I am personally aware of two deaths in the past year that resulted directly from intraarterial injection during transforaminal cervical epidural steroid procedures, neither of which were performed by ISIS instructors, nor have they been published.
Both cases, as one might expect, are now in litigation. I doubt that either of the practitioner/defendants would be inclined to participate in such a poll.

A closed-claims study similar to the efforts made by our anesthesiology brethren might better define the magnitude of the problem. This would not depend on self-reporting or physician recall, and the operative technique would be easily discernible in the medical record.

\section{ReFERENCES}

1. Derby R, Lee SH, Kim BJ, Chen Y, Seo KS. Complications following cervical epidural steroid injections by expert interventionalists in 2003. Pain Physician 2004; 7 : 445-450.

2. Heavner JE, Racz, GB; Jenigiri B, Lehman T, Day M. Sharp versus blunt needle: A comparative study of penetration of internal structures and bleeding in dogs. Pain Practice 2003; 3: 226.

Michael S. Gorback, MD

P.O. Box 58899

Webster TX 77598-8899 